\title{
KJA \\ Korean Journal of Anesthesiology \\ Intravenous non-opioid analgesia for peri- and postoperative pain management: a scientific review of intravenous acetaminophen and ibuprofen
}

\author{
Wonuk Koh ${ }^{1}$, Kimngan Pham Nguyen ${ }^{2}$, and Jonathan S. Jahr ${ }^{3}$ \\ ${ }^{I}$ Department of Anesthesiology and Pain Medicine, Asan Medical Center, University of Ulsan College of Medicine, \\ Seoul, Korea, ${ }^{2}$ Department of Anesthesiology and Perioperative Medicine, UCLA College of Arts and Letters, ${ }^{3}$ David \\ Geffen School of Medicine at UCLA Ronald Regan UCLA Medical Center, CA, USA
}

Pain is a predictable consequence following operations, but the management of postoperative pain is another challenge for anesthesiologists and inappropriately controlled pain may lead to unwanted outcomes in the postoperative period. Opioids are indeed still at the mainstream of postoperative pain control, but solely using only opioids for postoperative pain management may be connected with risks of complications and adverse effects. As a consequence, the concept of multimodal analgesia has been proposed and is recommended whenever possible. Acetaminophen is one of the most commonly used analgesic and antipyretic drug for its good tolerance and high safety profiles. The introduction of intravenous form of acetaminophen has led to a wider flexibility of its use during peri- and postoperative periods, allowing the early initiation of multimodal analgesia. Many studies have revealed the efficacy, safety and opioid sparing effects of intravenous acetaminophen. Intravenous ibuprofen has also shown to be well tolerated and demonstrated to have significant opioid sparing effects during the postoperative period. However, the number of randomized controlled trials confirming the efficacy and safety is small and should be used in caution in certain group of patients. Intravenous acetaminophen and ibuprofen are important options for multimodal postoperative analgesia, improving pain and patient satisfaction. (Korean J Anesthesiol 2015; 68: 3-12)

Key Words: Acetaminophen, Analgesia, Ibuprofen, Intravenous, Postoperative pain.

Corresponding author: Jonathan S. Jahr, M.D.

David Geffen School of Medicine at UCLA, Ronald Regan UCLA Medical Center, 757 Westwood Plaza, Suite 3325, Los Angeles, CA 90095-7403, USA

Tel: 1-310-267-8678, Fax: 1-310-267-3899

E-mail: jsjahr@mednet.ucla.edu

Received: April 17, 2014.

Revised: 1st, May 20, 2014; 2nd, July 11, 2014.

Accepted: July 15, 2014.

Korean J Anesthesiol 2015 February 68(1): 3-12 http://dx.doi.org/10.4097/kjae.2015.68.1.3

\section{Introduction}

Although acute pain is predictable after operations, the management of postoperative pain is indeed a difficult challenge for anesthesiologists. Despite the increased knowledge about nociception and advance in pharmacology, over $80 \%$ of surgical patients are reported to experience moderate pain and $31-37 \%$ of patients experience severe or extreme pain $[1,2]$. Inadequately controlled pain after surgery may result in many unwanted consequences, along with patient discomfort and suffering, in-

(c) This is an open-access article distributed under the terms of the Creative Commons Attribution Non-Commercial License (http://creativecommons.org/ licenses/by-nc/3.0/), which permits unrestricted non-commercial use, distribution, and reproduction in any medium, provided the original work is properly cited. 
creased risk of myocardial ischemia, impaired rehabilitation, impaired wound healing, delayed gastrointestinal motility, immune alterations, pulmonary complications due to poor respiratory effort, and increased risk of thromboembolism due to immobilization [3-8].

Traditionally, opioid-based analgesia has been the primary modality for most of the severe postoperative pain management. But, the use of opioids, especially when monomodal, have been associated with risks of complications and adverse effects $[9,10]$. The primary use of opioids are associated with respiratory depression, sedation, drowsiness, pruritus, skin rash, urinary retention, delayed gastrointestinal motility, and postoperative vomiting and nausea [11]. Furthermore, within the first 12 hours post-operation, over sedation related to postoperative analgesic use was observed in $72.7 \%$ of patients, which may have led to dangerous conditions [12].

Considering the conditions associated with opioid-based analgesia, the concept of "multimodal analgesia" has been proposed in the early 1990s to overcome the opioid induced adverse effects and at the same time, to achieve sufficient analgesia $[9,10]$. Based on the ladder of therapy for cancer pain, the proposed ladder of therapy for multimodal postoperative pain management is shown in Fig. 1 [13]. The rationale of this concept is through additive or synergetic effects between analgesics of different mechanism, will allow optimal level of analgesia. This will allow a reduction in any individual analgesic dose that may decrease the occurrence of adverse effects associated with overdose from a single analgesic [14]. Recently, the American Society of Anesthesiologists Task Force on Acute Pain Management has recommended utilization of multimodal analgesia management therapy whenever possible [4]. These include 1) Regional/central nerve blocks with local anesthetics; 2) "Around-the-clock" regimen of non-opioid analgesics consisting of nonsteroidal anti-inflammatory drugs (NSAIDs), cyclooxygenase-2 selective NSAIDs (COXIBs), and acetaminophen unless they are contraindicated.

Thus, according to the new guidelines proposed at 2012, as a part of the multimodal analgesia, the use of acetaminophen, NSAIDs, and COXIBs should always be considered for acute postoperative pain management. Although these agents may be insufficient as a single regimen to treat severe pain, they may be acceptable augmentation to opioids and may result a substantial decrease in opioid requirements, which is associated with the decrease or possible avoidance of opioid related side effects [9,14-17]. The utility of non-opioid analgesics are very broad, as they can be used preoperatively as a part of preemptive and preventive regimen, intraoperative usage to block surgical nociception along with opioids and regional anesthesia, and for postoperative pain control to increase the efficacy of opioids and reduce its side effects $[18,19]$.

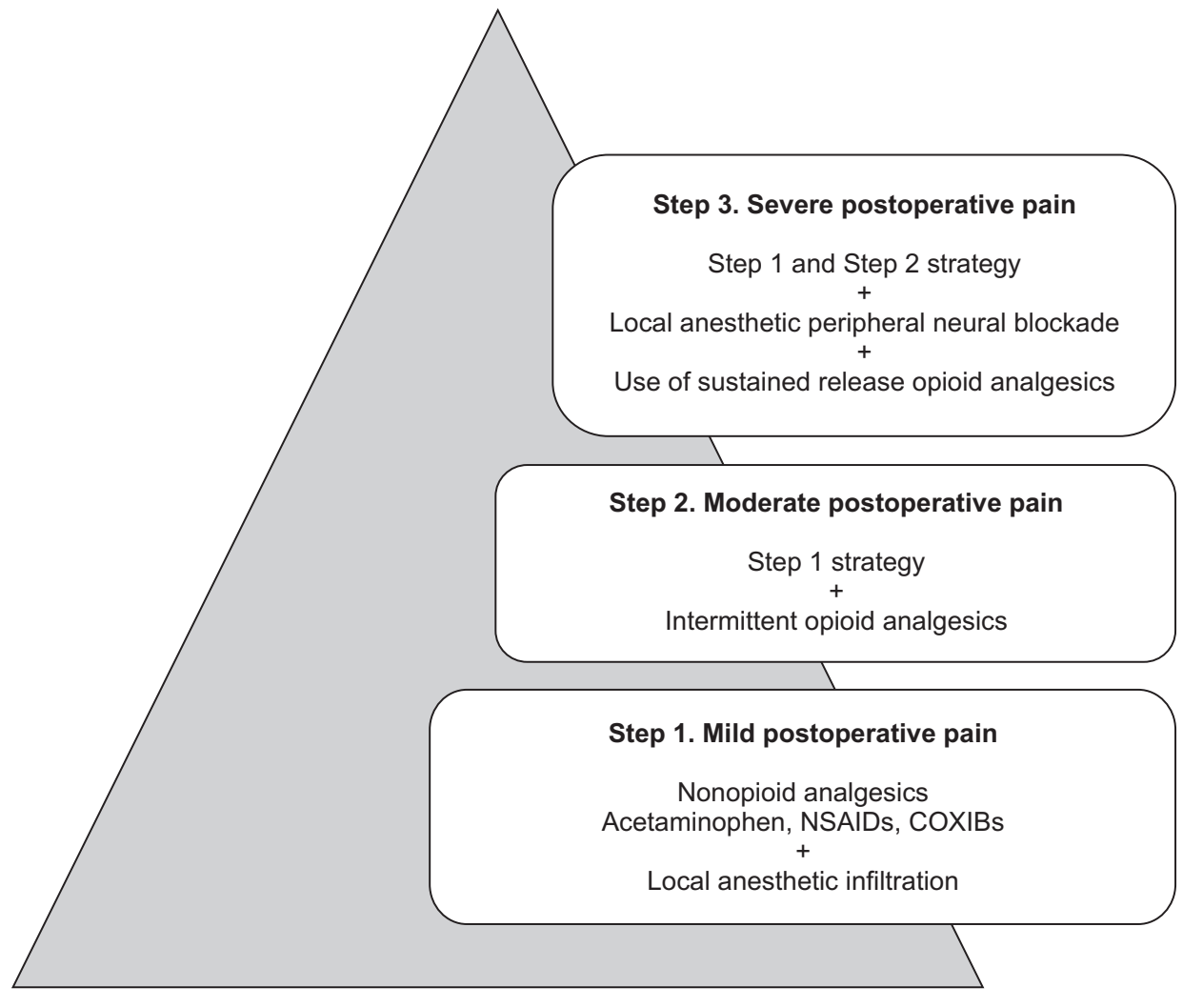

Fig. 1. The ladder of therapy for multimodal postoperative pain management. The figure is adapted from [13]. 
The non-opioid analgesics can be delivered in various routes including oral, rectal, intravenous, and recently intranasal formulation. And diverse number of NSAIDs, COXIBs, and other miscellaneous drugs (in example; nefopam, gabapentin, ketamine) have been studied and utilized for a part of multimodal analgesia. In the present topic, we will focus on the clinical uses, dosing, opioid-sparing effects, safety, and efficacy of the intravenous acetaminophen and intravenous ibuprofen.

\section{Intravenous Acetaminophen}

Acetaminophen (or paracetamol) was first used clinically in 1887 and has been widely marketed from the 1950s [20]. Since then, it has become one of the most frequently used and ordered antipyretic and analgesic drug, secondary to its high therapeutic index [20,21]. Acetaminophen has analgesic and antipyretic effects, but unlike the NSAIDs, it does not have peripheral antiinflammatory effects [22]. Furthermore, it does not affect the platelet function, therefore, making it useful during any time of operation [23].

The analgesic mechanism of acetaminophen is not completely understood. It has been known to be a centrally acting inhibitor of the prostaglandins via the cyclooxygenase (COX) pathway $[17,24]$. Acetaminophen has shown to rapidly enter the central nervous system and most of the actions involved in analgesia acts in the central nervous system $[25,26]$. In vitro, acetaminophen demonstrated a 4.4 times receptor selectiveness to COX2, compared with COX-1 [27]. It is known to act as nitric oxide pathway inhibitor through substance $\mathrm{P}$ or N-methyl-D-aspartate $[28,29]$, and strengthen the descending serotonergic inhibitory pathways [30]. Recently, active metabolites of acetaminophen presented to have effect on the cannabinoid receptors [31-33]. Acetaminophen, via this process, is de-acetylated in the spinal cord and then brain to $p$-aminophenol, and through conjugation with arachidonic acid, where it forms $\mathrm{N}$-arachidonoylphenolamine (AM404). AM404, a powerful facilitator of the transient receptor potential vanilloid subtype 1 receptor (TRPV1) and a ligand of cannabinoid type 1 receptors, inhibits the cellular anandamide uptake, resulting in an elevated level of endogenous cannabinoids (encannabinoids). The cellular anandamide uptake culminates in the triggering of nociceptors that is inhibited following acetaminophen administration. In animal studies, AM404 has shown to produce anti-nociception by activating TRPV1 in the brain [33].

Acetaminophen has been available in the market as oral and suppository form for many decades, and the intravenous form has been recently introduced and received its approval in Europe at 2002 and in United States at 2010. Currently, it has received approval for clinical use in approximately 80 countries around the world [17]. It has been available in Korea from 2007 (Perfal-
$\left.\operatorname{gan}^{\circledR}\right)$, but recently the supply has been stopped (2012) due to supplier marketing policies. The pro-drug form of intravenous acetaminophen, propacetamol, which is rapidly hydrolyzed in blood to acetaminophen, has been available in Korea since 1995 and is currently in supply by various companies. Introduction of intravenous acetaminophen has provided benefits to the periand postoperative pain management compared to the previous oral or rectal formulations. It is a convenient, fast-acting, safe analgesic which is readily usable at the perioperative period, allowing the early initiation of multimodal analgesia possible $[14,34]$. The intravenous route also enables the delivery of this drug during the immediate postoperative period, when medication via oral or rectal route is difficult or impossible.

After intravenous administration of acetaminophen, a rapid and high plasma concentration is achieved within 5 minutes, with the initiation of pain relief also occurring within five minutes [34]. Peak plasma concentration occurs at the completion of a 15 minute administration, and that is on the order of $30 \mathrm{~min}$ utes faster than oral formulation $[34,35]$. Intravenously administered acetaminophen rapidly crosses the blood-brain barrier. Because of its high lipid solubility and low protein binding properties, acetaminophen is readily detectable in the cerebrospinal fluid (CSF) within minutes after intravenous delivery, and the concentrations in the CSF have been demonstrated to be directly proportional to plasma levels after intravenous doses between $500 \mathrm{mg}$ to $2,000 \mathrm{mg}[14,26,36,37]$. Therefore, the analgesic profiles are parallel to the concentration-time curve in the CSF and the concentration-time curve in the plasma [36]. After standard infusion of $1 \mathrm{~g}$ of acetaminophen for 15 minutes in the adult, the maximum plasma concentration $\left(\mathrm{C}_{\max }\right)$ was reported to be 29.9 $\mathrm{mg} / \mathrm{L}$ immediately after infusion, $26.0 \pm 7.7 \mathrm{mg} / \mathrm{L} 4$ hours after infusion, and $28.4 \pm 21.2 \mathrm{mg} / \mathrm{L} 8$ hours after infusion, which is approximately $70-75 \%$ higher than the $\mathrm{C}_{\max }$ of an equivalent oral dose. Indeed, the intravenous administration resulted in significantly increased concentration in the central nervous system compared to oral delivery $\left(C_{\max }=5.94\right.$ vs. $\left.3.72 \mathrm{mg} / \mathrm{L}\right)$. The time to reach maximum concentration $\left(\mathrm{T}_{\max }\right)$ for the intravenous acetaminophen after 15 minute infusion was approximately 30 minutes faster compared with oral formulation $[11,17,38]$. These differences in the pharmacokinetics of intravenous acetaminophen compared with the oral form arise from the fact that the intravenous form does not go through the first pass effect which the oral form does, which is a well known phenomenon with intravenous vs. oral drugs. The main pharmacokinetic parameters of intravenous acetaminophen is shown in Table 1. The metabolism and excretion of acetaminophen did not demonstrate significant difference between the routes of administration. In the liver, acetaminophen is metabolized by sulfation, oxidation, and glucuronidation. In the oxidative pathway, cytochrome P450 isoenzyme CYP2E1 produces $\mathrm{N}$-acetyl-p-benzoquinone imine 
(NAPQI). NAPQI is then conjugated with intracellular glutathione and excreted in the urine as 3'-[S-cysteinyl] acetaminophen, 3'-S-metyhlacetaminophen, and acetaminophen mercapturate. After acute acetaminophen overdose or heavy alcohol consumption, glutathione storage can be depleted, and NAPQI may cause hepatotoxicity [39-41].

The dose of intravenous acetaminophen in adolescents and adults is $1 \mathrm{~g}$ every 4-6 hours, with a maximum daily dose of 4 grams. In children of 2 years of age and older, and adolescents, and adults weighing less than $50 \mathrm{~kg}, 15 \mathrm{mg} / \mathrm{kg}$ should be administered at the same interval. Under 2 years of age, children and infants should receive no more than $10 \mathrm{mg} / \mathrm{kg}$, and neonates and premature infants probably on $7.5 \mathrm{mg} / \mathrm{kg}$, although exact dosing has not been established. The elimination half-life is $2-3$ hours, and the duration of analgesic effect is approximately 4-6 hours and it may be prolonged in infants, neonates, and patients with renal impairment $[42,43]$.

Numerous studies demonstrating the safety and efficacy of intravenous acetaminophen have been conducted since its introduction. Recently, several detailed articles reviewing the previous studies have been published. In 2011, Macario and Royal reviewed the previously published clinical trials of the efficacy and safety of perioperative intravenous acetaminophen for postoperative pain control that were randomized and placebo-controlled. Sixteen articles involving 1,464 patients were reviewed. The investigators discovered that patients had lower pain scores in 12 of 14 trials and postoperative opioid use was reduced in 10 of 14 trials when receiving perioperative acetaminophen [44]. Another systematic review of 36 studies involving 3,896 patients found that $37 \%$ of patients receiving a single intravenous dose of paracetamol (acetaminophen) or propacetamol had experienced a minimum of $50 \%$ pain relief for 4 hours compared to $16 \%$ when receiving placebo, with a numbers needed to treat (NNT) of 4.0 (3.5-4.8) for benefit. At 6 hours, $26 \%$ of patients receiving paracetamol or propacetamol still experienced $50 \%$ pain relief, with a NNT of 5.3 (4.2-6.7). Furthermore, patients receiving paracetamol demonstrated $30 \%$ reduction in opioid consumption during $0-4$ hours and $16 \%$ reduction in opioid consumption during 0-6 hours of postoperative period compared with patients receiving placebo [45].

The utility of acetaminophen for postoperative pain control and opioid-sparing has also been studied in pediatric patients. A systematic review aimed to assess the opioid-sparing effect of NSAIDs and acetaminophen reported that 7 of 13 (54\%) treatment arms which received acetaminophen yield significant postoperative opioid-sparing [46]. However, the drug delivery route in most studies were rectal, and only 2 studies by a same group of researchers used intravenous acetaminophen, as a single agent with opioid or in combination with ketorolac, which both reported significant fentanyl sparing $[47,48]$. A recent randomized controlled trial compared the efficacy and morphine sparing effect of intravenous acetaminophen given as a primary analgesic after major abdominal or thoracic surgery in neonates and infants under 1 year of age [49]. In this study, compared with morphine (control) group, the cumulative morphine dose was $66 \%$ decreased in the acetaminophen group, but the total morphine rescue dose between the two groups did not vary significantly, indicating a similar efficacy for analgesia in either groups. This

Table 1. Main Pharmacokinetic Parameters of Acetaminophen following Intravenous Administration of $5 \mathrm{~g}$ during the First $24 \mathrm{hr}$ with a $2 \mathrm{~g}$ Starting Dose

\begin{tabular}{|c|c|c|c|c|c|}
\hline & $\mathrm{T}_{\max } *(\mathrm{hr})$ & $\mathrm{C}_{\max }(\mu \mathrm{g} / \mathrm{ml})$ & $\mathrm{C}_{\min }(\mu \mathrm{g} / \mathrm{ml})$ & $\mathrm{T} 1 / 2 \gamma(\mathrm{hr})$ & $\begin{array}{c}\mathrm{AUC}_{0-\tau} \\
(\mathrm{Hr} * \mu \mathrm{g} / \mathrm{ml})\end{array}$ \\
\hline \multicolumn{6}{|c|}{$1^{\text {st }}$ infusion $(2 \mathrm{~g})$} \\
\hline Mean \pm SD & 0.25 & $67.9 \pm 21.8$ & $6.19 \pm 2.27$ & - & $112.3 \pm 22.5$ \\
\hline Min-max & $0.25-0.50$ & $30.7-115$ & $3.33-12.6$ & - & $82.0-173.2$ \\
\hline \multicolumn{6}{|c|}{$2^{\text {nd }}$ infusion $(1 \mathrm{~g})$} \\
\hline Mean \pm SD & 0.25 & $45.0 \pm 13.4$ & $4.34 \pm 1.83$ & - & $72.7 \pm 20.2$ \\
\hline Min-max & $0.25-0.50$ & $22.2-84.9$ & $2.53-9.89$ & - & $54.1-135.2$ \\
\hline \multicolumn{6}{|c|}{$3^{\text {rd }}$ infusion $(1 \mathrm{~g})$} \\
\hline Mean \pm SD & 0.25 & $37.8 \pm 10.2$ & $4.08 \pm 1.87$ & - & - \\
\hline Min-max & $0.25-0.25$ & $22.0-60.2$ & $2.05-9.49$ & - & - \\
\hline \multicolumn{6}{|c|}{$4^{\text {th }}$ infusion $(1 \mathrm{~g})$} \\
\hline Mean \pm SD & 0.25 & $39.0 \pm 11.2$ & $4.20 \pm 2.00$ & - & - \\
\hline Min-max & $0.25-0.25$ & $68.0-20.1$ & $1.74-9.97$ & - & - \\
\hline \multicolumn{6}{|c|}{$5^{\text {th }}$ infusion $(1 \mathrm{~g})$} \\
\hline Mean \pm SD & 0.25 & $42.8 \pm 10.2$ & $3.82 \pm 1.94$ & $7.0 \pm 2.3$ & $66.0 \pm 18.1$ \\
\hline Min-max & $0.25-0.25$ & $26.0-71.4$ & $1.74-9.58$ & $4.9-15.3$ & $48.5-120.9$ \\
\hline
\end{tabular}

The table is adapted from $\left[51 \mathrm{sic}\right.$ ] with permission for reuse. $\mathrm{C}_{\max }$ : maximum observed concentration, $\mathrm{T}_{\max }$ : time to reach $\mathrm{C}_{\max }, \mathrm{C}_{\min }$ : minimum concentration observed within a dosing interval, $\mathrm{T} 1 / 2 \gamma$ : terminal half-life, $\mathrm{AUC}_{0-\tau}$ : area under the concentration-time curve during a dosing interval. *Median (min - max). 
study provided important documentation that intravenous acetaminophen can be a potential alternative to opioids as a primary analgesic agent for postoperative pain control in neonates and young infants [49].

Although many articles reviewed the efficacy of intravenous acetaminophen for postoperative pain control and opioid reduction, there were few studies reporting the effect of acetaminophen for reducing opioid related adverse effects in the postoperative period. A systematic review of intravenous acetaminophen for the effect in nausea and vomiting after general anesthesia has been recently published [16]. This meta-analysis analyzed 30 studies involving 2,364 patients, of whom 1,223 were in the acetaminophen group and 1,141 were in the placebo group. Intravenous acetaminophen was associated with a relative risk for postoperative nausea of 0.73 and 0.63 for vomiting, indicating a decrease in postoperative nausea and vomiting (PONV). The timing of intravenous acetaminophen administration was important: most effective when given before and during the surgery and less when given after surgery after the onset of postoperative pain. However, the reduction of PONV was related to a the decrement in postoperative pain and not associated with postoperative opioid consumption, indicating that pain itself maybe an important risk factor for PONV [16].

Intravenous acetaminophen is known to be safe and well tolerated, sharing similar safety profiles of the rectal and oral formulations, with an adverse event profile similar to placebo [50-52]. Significant adverse reactions associated with intravenous acetaminophen are extremely rare, occurring at an approximate incidence of fewer than 1/10,000 [43]. Typically reported adverse events include hypotension, malaise, hypersensitivity reaction, liver enzyme elevation, and thrombocytopenia [43]. The most well-known safety concern with the use of acetaminophen is the potential hepatotoxicity when used above recommended doses ( $>4 \mathrm{~g} /$ day for adults over $50 \mathrm{~kg}$ ). To evaluate the safety of intravenous acetaminophen, a randomized double-blinded placebocontrolled study was conducted, showing no significant difference in the treatment-emergent adverse event (TEAE) between the placebo group $(\mathrm{N}=110)$ and the intravenous acetaminophen group $(\mathrm{N}=134)$, and only 1 patient in the placebo group showed an increase in hepatic aminotransferase [53]. In another open label prospective study involving 213 patients, intravenous acetaminophen was administered in different doses $(650 \mathrm{mg} \mathrm{q}$ $4 \mathrm{hr}: \mathrm{N}=91,1,000 \mathrm{mg} \mathrm{q} 6 \mathrm{hr}: \mathrm{N}=92$ ) in an "around-the-clock" regimen for 5 days compared to the control group, which was standard-of-care $(\mathrm{N}=30)$. Typical medications considered appropriate for the treatment of fever or pain were administered in the standard-of-care treatment arm. The prevalence of hepatic TEAEs considered to be correlated with acetaminophen was low and minor, with no major hepatic issues related to intravenous acetaminophen administration [54]. The depleted glutathione storage does not appear to be an increased risk factor for patients with severe hepatic disease and are at an increased risk for hepatotoxicity; therapeutic doses of acetaminophen are unlikely to precipitate severe hepatic TEAEs $[55,56]$.

\section{Intravenous Ibuprofen}

Ibuprofen is a propionic acid derivative, sharing the antiinflammatory, antipyretic and analgesic effects which most other NSAIDs have. It was developed by the Boots group of United Kingdom in the 1960s [57]. The oral form has been marketed in 1969 in the United Kingdom and in 1974 in the United States. Since its approval in the United States and United Kingdom, ibuprofen has been primarily used as an over-the-counter (OTC) drug, making it one of the most frequently used oral NSAID. Also in Korea, it has been approved for OTC supply and is available to purchase this drug without prescriptions. The intravenous form of ibuprofen $\left(\right.$ Caldolor $\left.^{\circledR}\right)$ has been approved for the treatment of mild to moderate pain, and for the treatment of moderate to severe pain as augmentation to opioids in the United States at June 2009 [58,59]. Recently, intravenous ibuprofen has been approved in Korea for the treatment of pain and fever and is available. Before the approval of intravenous ibuprofen ketorolac was the only intravenous NSAID in the United States.

The analgesic effect of ibuprofen is related to inhibition of the cyclooxygenase isoenzymes. Administration of ibuprofen causes a rapid, reversible and competitive inhibition of COX-1 and COX-2 enzymes, preventing the production of prostaglandins [60,61]. Like majority of other NSAIDs, ibuprofen's analgesic, antipyretic, and anti-inflammatory activities appear to operate mainly through inhibition of the COX-2 isoenzyme, whereas inhibition of COX-1 is responsible for the unwanted side effects (mainly on the gastrointestinal tract and kidney) [61].

The selectivity of individual NSAIDs to COX-1 and COX-2 are closely related to the probability of unwanted adverse effects. A drug that has a ratio of COX-1: COX-2 inhibition greater than 1 is likely to be associated with adverse events than those with COX-1 : COX-2 inhibition ratio less than $1[62,63]$. Oral ibuprofen 2,400 mg/day demonstrated inhibition of COX-1 activity by $88.7 \%$ and COX-2 activity by $71.4 \%$ in a healthy volunteer study [64]. The relative ratio of COX-1 : COX-2 inhibition of NSAIDs are summarized in Fig. 2 [65]. Ibuprofen inhibits COX-1 2.5 times more than COX-2, where as ketorolac inhibits COX-1 over 300 times more than COX-2 in humans.

As with many other NSAIDs, ibuprofen is composed of a racemic mixture of S- and R-isomers. While the R-enantiomer is pharmacologically inactive in vivo and in vitro, the S-enantiomer has proven to be the etiology of the clinical activity of ibuprofen. However, the R-enantiomer is slowly and incompletely (approximately 60\%) converted to the active S-enantiomer in 
adult plasma, thereby acting as a reservoir for maintenance of the circulating concentration of ibuprofen. For the treatment of pain in adults, the recommended dose of intravenous ibuprofen is 400 to $800 \mathrm{mg}$ every 6 hours. For fever, $400 \mathrm{mg}$ is initially infused and $400 \mathrm{mg}$ every 4 to 6 hours or 100 to $200 \mathrm{mg}$ every 4 hours as required. The infusion time must be at a minimum of thirty minutes. Before infusion, intravenous ibuprofen should be diluted to a final concentration of $4 \mathrm{mg} / \mathrm{ml}$ or less, resulting in a final solution of no less than $100 \mathrm{ml}(400 \mathrm{mg})$ or $200 \mathrm{ml}(800$ $\mathrm{mg})$. Intravenous ibuprofen has been formulated in $400 \mathrm{mg}(4$ $\mathrm{ml})$ and $800 \mathrm{mg}(8 \mathrm{ml})$ dosages; the $400 \mathrm{mg}$ packaged dose is available in Korea.

The pharmacokinetic properties of intravenous ibuprofen were studied compared to healthy adult volunteers and febrile hospitalized patients. Febrile patients were further stratified to critically ill or not. In the study of febrile patients, 120 adult subjects were enrolled and received a placebo or $100 \mathrm{mg}, 200 \mathrm{mg}$, $400 \mathrm{mg}$ intravenous ibuprofen [66]. The area under the curve for plasma concentration-time from 0 hour to 4 hours $\left(\mathrm{AUC}_{0-4}\right)$ after initial administration of the drug, was determined in this study. The $\mathrm{AUC}_{0-4}$ was determined to be proportional for the $200 \mathrm{mg}$ and $400 \mathrm{mg}$ levels of ibuprofen in this study. Furthermore, compared with the non-critically ill population, the plasma concentration of ibuprofen in all administered doses was significantly decreased in the critically ill population [66]. In the healthy adult volunteer study, which was a single dose placebo-controlled crossover trial, 12 healthy adult were enrolled to receive single intravenous dose of ibuprofen or placebo, and oral administration of ibuprofen or placebo $(800 \mathrm{mg})$. First, intravenous ibuprofen was compared with oral ibuprofen. The pharmacokinetic parameters were observed to be similar in either route of administration, except intravenous infusion of ibuprofen demonstrated higher $\mathrm{C}_{\max }$, and faster $\mathrm{T}_{\max }$ compared with oral administration [67]. Second, rapid intravenous infusion of $800 \mathrm{mg}$ ibuprofen within 5-7 minutes were compared with oral $800 \mathrm{mg}$ administration and further compared with historical or modeled data of intravenous ibuprofen of $400 \mathrm{mg}$ and 800 $\mathrm{mg}$, slowly infused over 30 or 60 minutes. The rapid infusion of ibuprofen $800 \mathrm{mg}$ (5-7 minutes) and the modeled data of 5-7 minute infusion of ibuprofen $400 \mathrm{mg}$ showed to have significantly increased $\mathrm{C}_{\max }$ values and shorter $\mathrm{T}_{\max }$ values compared with 30 or 60 minute infusion of the same dose of ibuprofen [58] (Table 2).

To analyze the therapeutic efficacy of intravenous ibuprofen for the management of postoperative pain in adult patients who underwent orthopedic or abdominal surgery, three randomized double blinded placebo controlled trials were conducted. In two studies, at the start of wound closure in patients who underwent orthopedic or abdominal surgery, intravenous ibuprofen was initially administered intraoperatively [68,69]. Total of 319 patients and 406 patients were enrolled in each study and randomized to receive $400 \mathrm{mg}$ or $800 \mathrm{mg}$ of intravenous ibuprofen or placebo every 6 hours for up to 120 hours [68], and $800 \mathrm{mg}$ of intravenous ibuprofen or placebo every 6 hours for 24 hour postoperative period [69]. In both studies, during the first 24 hours after operation, the administration of $800 \mathrm{mg}$ of intravenous ibuprofen resulted in a significant decrease in median

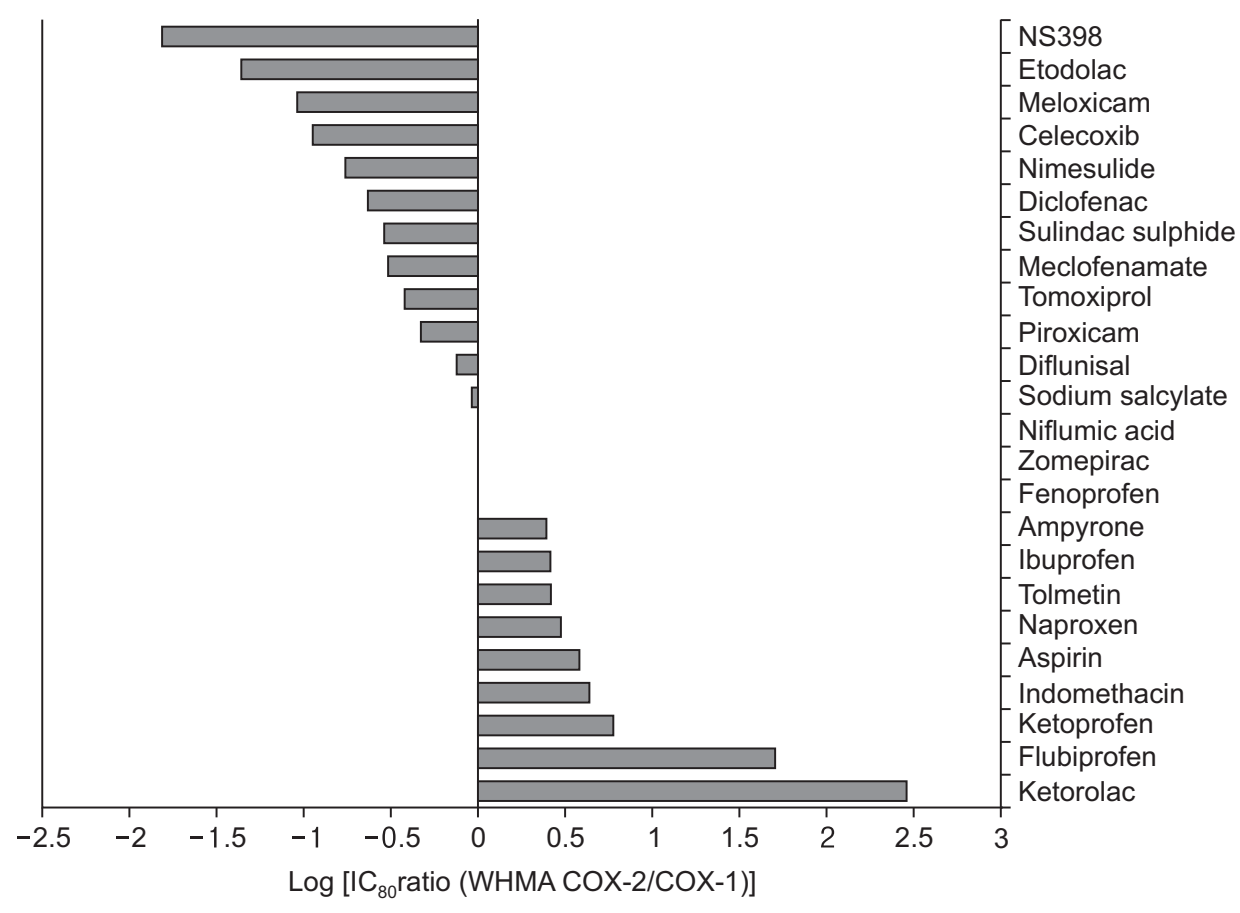

Fig. 2. The inhibition of COX-2 relative to COX-1 in current NSAIDs. The figure is adapted from [65]. 
Table 2. Main Pharmacokinetic Parameters of Ibuprofen following Intravenous Single Dose Administration of $800 \mathrm{mg}$ or $400 \mathrm{mg}$ Infused over 5-7, 30 or 60 Minutes Compared with a Single Same Oral Dose

\begin{tabular}{lccc}
\hline \multicolumn{1}{c}{ Ibuprofen dose and time } & $\begin{array}{c}\mathrm{C}_{\max } \\
(\mu \mathrm{g} / \mathrm{ml})\end{array}$ & $\begin{array}{c}\mathrm{T}_{\max } \\
(\mathrm{hr})\end{array}$ & $\begin{array}{c}\mathrm{T}_{1 / 2} \\
(\mathrm{hr})\end{array}$ \\
\hline 800 mg & & & \\
IV ibuprofen 5-7 min infusion & $120 \pm 13$ & $0.11 \pm 0.01$ & \\
IV ibuprofen 30 min infusion & $84.17^{*}$ & $0.54^{*}$ & \\
IV ibuprofen 60 min infusion & 72.6 & 1.0 & 2.44 \\
Oral tablet & $63 \pm 12$ & $1.50 \pm 0.58$ & \\
400 mg & & & \\
IV ibuprofen 5-7 min infusion & $59.76^{*}$ & $0.1^{*}$ & \\
IV ibuprofen 30 min infusion & $39.8 \pm 17.8$ & 0.5 & \\
IV ibuprofen 60 min infusion & 39.2 & 1.0 & 2.22 \\
Oral tablet & $30.3^{*}$ & $1.62^{*}$ & \\
\hline
\end{tabular}

The table is adapted from [58 sic] with permission for reuse. IV: intravenous, min: minute, hr: hour, $\mathrm{C}_{\max }$ : maximum observed concentration, $\mathrm{T}_{\max }$ : time to reach $\mathrm{C}_{\max }, \mathrm{T}_{1 / 2}$ : elimination half-life. *Modeled data.

morphine administered during the first 24 hours after operation (22 and 19\%) compared with placebo. Compared with placebo both doses of intravenous ibuprofen administered every 6 hours resulted in a significant decrease in pain scores at rest and movement during the first 24 hours. In another randomized trial, placebo or intravenous ibuprofen $800 \mathrm{mg}$ was initially administered preoperatively in 185 adult orthopedic patients, considering the effect of ibuprofen in preemptive analgesia [70]. In this study, patients received four more scheduled doses of placebo or $800 \mathrm{mg}$ ibuprofen every 6 hours, and after 24 hours, further administration was delivered as needed to a maximum of 120 hours. There was a significant reduction in mean pain score at movement and rest compared with placebo during the first 6 to 28 postoperative hours. Compared with placebo, a significant decrease in mean morphine consumption (30.9\%) was observed in the ibuprofen group. Compared with placebo group, there was also a substantial reduction in immediate postoperative pain in the ibuprofen group demonstrating the possible preemptive analgesic effect of preoperatively administered ibuprofen [70]. In all three studies, there was no significant variance in the overall incidence of TEAE, including severe adverse events, and the daily dose of ibuprofen 3,200 mg was well tolerated [68-70]. Further studies are underway, including the effect of intravenous ibuprofen for the treatment of myalgias after electroconvulsive therapy, acute migraine exacerbation, inguinal hernia repair and pediatric patients [59].

Intravenous ibuprofen was commonly well tolerated by patients in the multiple clinical trials evaluating the efficacy of intravenous ibuprofen for pain and fever treatment [66,68-72]. Furthermore, no significant variance was witnessed in the outcome of 455 patients who received either intravenous ibuprofen or placebo for the treatment of sepsis [73]. The most common TEAE following intravenous ibuprofen treatment in postoperative pain trials was nausea, flatulence, hemorrhage, vomiting, headache, dizziness and urinary retention. The most common TEAE following intravenous ibuprofen for the treatment in fever was anemia and eosinophilia [59]. Other possible adverse effect of ibuprofen is similar with other NSAIDs. It may elevate the risk of cardiovascular thrombotic events, gastrointestinal adverse events consisting of gastrointestinal bleeding and ulceration, increase in liver enzyme, onset or worsening of hypertension, fluid retention and serious skin adverse events. Ibuprofen is contraindicated in patients with asthma, allergic reactions to aspirin and other NSAIDs and patients undergoing coronary artery interventions or coronary artery bypass surgery. Ibuprofen should be utilized in caution for patients with a history of gastrointestinal bleeding or ulcer, hepatic and renal diseases, hypertension, heart failure and elderly patients [59]. If significant bleeding is expected or risk of bleeding after surgery is possible, the administration of pre- or perioperative ibuprofen should be reconsidered, as oral ibuprofen is known to dose proportionally significantly inhibit the activity of thromboxane B2, platelet aggregation and prolong bleeding time compared with placebo $[64,74]$.

\section{Summary}

Based on the scientific reviews of both intravenous acetaminophen and ibuprofen, it should be clear that both are safe and effective if used as directed, and improve pain and satisfaction scores. Additionally, they decrease opioid use and likely contribute to fewer adverse events, due to this, or possibly as they may have fewer adverse events when administered intravenously (lack of first pass effect, controlled administration where known dosing regimens are employed, and increased vigilance in a hospital or clinic setting compared to home use/overuse).

Preemptive use of both agents appears to convey even greater relief or prevention of pain, although confirmatory studies would be helpful in large cohorts of diverse patients. Also, long term outcome with use of the intravenous agents is lacking, and perhaps provides improvements, although distinguishing between intravenous and other formulations over time would be challenging.

In conclusion, intravenous acetaminophen and ibuprofen are important options either alone or in combination, for management of pain and fever, and reductions in opioid use, validating the World Health Organization's pain ladder [13], with use of these medications and regional anesthesia as the first line in the mitigation of acute pain. 


\section{References}

1. Carr DB, Goudas LC. Acute pain. Lancet 1999; 353: 2051-8.

2. Apfelbaum JL, Chen C, Mehta SS, Gan TJ. Postoperative pain experience: results from a national survey suggest postoperative pain continues to be undermanaged. Anesth Analg 2003; 97: 534-40.

3. Kehlet H, Dahl JB. Anaesthesia, surgery, and challenges in postoperative recovery. Lancet 2003; 362: 1921-8.

4. American Society of Anesthesiologists Task Force on Acute Pain Management. Practice guidelines for acute pain management in the perioperative setting: an updated report by the American Society of Anesthesiologists Task Force on Acute Pain Management. Anesthesiology 2012; 116: 248-73.

5. Desborough JP. The stress response to trauma and surgery. Br J Anaesth 2000; 85: 109-17.

6. Gandhi K, Heitz JW, Viscusi ER. Challenges in acute pain management. Anesthesiol Clin 2011; 29: 291-309.

7. Holte K, Kehlet H. Postoperative ileus: a preventable event. Br J Surg 2000; 87: 1480-93.

8. Lucas CE, Vlahos AL, Ledgerwood AM. Kindness kills: the negative impact of pain as the fifth vital sign. J Am Coll Surg 2007; $205:$ 101-7.

9. Kehlet H, Dahl JB. The value of "multimodal" or "balanced analgesia" in postoperative pain treatment. Anesth Analg 1993; 77: 1048-56.

10. Dahl JB, Rosenberg J, Dirkes WE, Mogensen T, Kehlet H. Prevention of postoperative pain by balanced analgesia. Br J Anaesth 1990; 64: 518-20.

11. Jahr JS, Filocamo P, Singh S. Intravenous acetaminophen: a review of pharmacoeconomic science for perioperative use. Am J Ther 2013; 20: 189-99.

12. Taylor S, Voytovich AE, Kozol RA. Has the pendulum swung too far in postoperative pain control? Am J Surg 2003; 186: 472-5.

13. Crews JC. Multimodal pain management strategies for office-based and ambulatory procedures. JAMA 2002; 288: 629-32.

14. Jahr JS, Lee VK. Intravenous acetaminophen. Anesthesiol Clin 2010; 28: 619-45.

15. Beaulieu P. Non-opioid strategies for acute pain management. Can J Anaesth 2007; 54: 481-5.

16. Apfel CC, Turan A, Souza K, Pergolizzi J, Hornuss C. Intravenous acetaminophen reduces postoperative nausea and vomiting: a systematic review and meta-analysis. Pain 2013; 154: 677-89.

17. Smith HS. Perioperative intravenous acetaminophen and NSAIDs. Pain Med 2011; 12: 961-81.

18. Argoff CE. Recent management advances in acute postoperative pain. Pain Pract 2014; 14: 477-87.

19. Khalili G, Janghorbani M, Saryazdi H, Emaminejad A. Effect of preemptive and preventive acetaminophen on postoperative pain score: a randomized, double-blind trial of patients undergoing lower extremity surgery. Clin Anesth 2013; 25: 188-92.

20. Bertolini A, Ferrari A, Ottani A, Guerzoni S, Tacchi R, Leone S. Paracetamol: new vistas of an old drug. CNS Drug Rev 2006; 12: 250-75.

21. Kaufman DW, Kelly JP, Rosenberg L, Anderson TE, Mitchell AA. Recent patterns of medication use in the ambulatory adult population of the United States: the Slone survey. JAMA 2002; 287: 337-44.

22. Niemi TT, Backman JT, Syrjälä MT, Viinikka LU, Rosenberg PH. Platelet dysfunction after intravenous ketorolac or propacetamol. Acta Anaesthesiol Scand 2000; 44: 69-74.

23. Cattabriga I, Pacini D, Lamazza G, Talarico F, Di Bartolomeo R, Grillone G, et al. Intravenous paracetamol as adjunctive treatment for postoperative pain after cardiac surgery: a double blind randomized controlled trial. Eur J Cardiothorac Surg 2007; 32: 527-31.

24. Boutaud O, Aronoff DM, Richardson JH, Marnett LJ, Oates JA. Determinants of the cellular specificity of acetaminophen as an inhibitor of prostaglandin H(2) synthases. Proc Natl Acad Sci U S A 2002; 99: 7130-5.

25. Smith HS. Potential analgesic mechanisms of acetaminophen. Pain Physician 2009; 12: 269-80.

26. Kumpulainen E, Kokki H, Halonen T, Heikkinen M, Savolainen J, Laisalmi M. Paracetamol (acetaminophen) penetrates readily into the cerebrospinal fluid of children after intravenous administration. Pediatrics 2007; 119: 766-71.

27. Hinz B, Cheremina O, Brune K. Acetaminophen (paracetamol) is a selective cyclooxygenase-2 inhibitor in man. FASEB J 2008; 22: $383-90$.

28. Björkman R, Hallman KM, Hedner J, Hedner T, Henning M. Acetaminophen blocks spinal hyperalgesia induced by NMDA and substance P. Pain 1994; 57: 259-64.

29. Bujalska M. Effect of nitric oxide synthase inhibition on antinociceptive action of different doses of acetaminophen. Pol J Pharmacol 2004; 56: 605-10.

30. Pickering G, Esteve V, Loriot MA, Eschalier A, Dubray C. Acetaminophen reinforces descending inhibitory pain pathways. Clin Pharmacol Ther 2008; 84: 47-51.

31. Högestätt ED, Jönsson BA, Ermund A, Andersson DA, Björk H, Alexander JP, et al. Conversion of acetaminophen to the bioactive $\mathrm{N}$-acylphenolamine AM404 via fatty acid amide hydrolase-dependent arachidonic acid conjugation in the nervous system. J Biol Chem 2005; 280: 31405-12.

32. Ottani A, Leone S, Sandrini M, Ferrari A, Bertolini A. The analgesic activity of paracetamol is prevented by the blockade of cannabinoid CB1 receptors. Eur J Pharmacol 2006; 531: 280-1.

33. Mallet C, Barrière DA, Ermund A, Jönsson BA, Eschalier A, Zygmunt PM, et al. TRPV1 in brain is involved in acetaminophen-induced antinociception. PLoS One 2010; 5: e12748.

34. Moller PL, Sindet-Pedersen S, Petersen CT, Juhl GI, Dillenschneider A, Skoglund LA. Onset of acetaminophen analgesia: comparison of oral and intravenous routes after third molar surgery. Br J Anaesth 2005; 94: 642-8. 
35. Holmer Pettersson P, Owall A, Jakobsson J. Early bioavailability of paracetamol after oral or intravenous administration. Acta Anaesthesiol Scand 2004; 48: 867-70.

36. Bannwarth B, Netter P, Lapicque F, Gillet P, Pere P, Boccard E, et al. Plasma and cerebrospinal fluid concentrations of paracetamol after a single intravenous dose of propacetamol. Br J Clin Pharmacol 1992; 34: 79-81.

37. Jensen LS, Valentine J, Milne RW, Evans AM. The quantification of paracetamol, paracetamol glucuronide and paracetamol sulphate in plasma and urine using a single high-performance liquid chromatography assay. J Pharm Biomed Anal 2004; 34: 585-93.

38. Flouvat B, Leneveu A, Fitoussi S, Delhotal-Landes B, Gendron A. Bioequivalence study comparing a new paracetamol solution for injection and propacetamol after single intravenous infusion in healthy subjects. Int J Clin Pharmacol Ther 2004; 42: 50-7.

39. Gelotte CK, Auiler JF, Lynch JM, Temple AR, Slattery JT. Disposition of acetaminophen at 4, 6, and 8 g/day for 3 days in healthy young adults. Clin Pharmacol Ther 2007; 81: 840-8.

40. Dart RC, Bailey E. Does therapeutic use of acetaminophen cause acute liver failure? Pharmacotherapy 2007; 27: 1219-30.

41. Kuffner EK, Green JL, Bogdan GM, Knox PC, Palmer RB, Heard K, et al. The effect of acetaminophen (four grams a day for three consecutive days) on hepatic tests in alcoholic patients--a multicenter randomized study. BMC Med 2007; 5: 13.

42. Palmer GM, Atkins M, Anderson BJ, Smith KR, Culnane TJ, McNally CM, et al. I.V. acetaminophen pharmacokinetics in neonates after multiple doses. Br J Anaesth 2008; 101: 523-30.

43. Duggan ST, Scott LJ. Intravenous paracetamol (acetaminophen). Drugs 2009; 69: 101-13.

44. Macario A, Royal MA. A literature review of randomized clinical trials of intravenous acetaminophen (paracetamol) for acute postoperative pain. Pain Pract 2011; 11: 290-6.

45. McNicol ED, Tzortzopoulou A, Cepeda MS, Francia MB, Farhat T, Schumann R. Single-dose intravenous paracetamol or propacetamol for prevention or treatment of postoperative pain: a systematic review and meta-analysis. Br J Anaesth 2011; 106: 764-75.

46. Wong I, St John-Green C, Walker SM. Opioid-sparing effects of perioperative paracetamol and nonsteroidal anti-inflammatory drugs (NSAIDs) in children. Paediatr Anaesth 2013; 23: 475-95.

47. Hong JY, Kim WO, Koo BN, Cho JS, Suk EH, Kil HK. Fentanyl-sparing effect of acetaminophen as a mixture of fentanyl in intravenous parent-/nurse-controlled analgesia after pediatric ureteroneocystostomy. Anesthesiology 2010; 113: 672-7.

48. Hong JY, Won Han S, Kim WO, Kil HK. Fentanyl sparing effects of combined ketorolac and acetaminophen for outpatient inguinal hernia repair in children. J Urol 2010; 183: 1551-5.

49. Ceelie I, de Wildt SN, van Dijk M, van den Berg MM, van den Bosch GE, Duivenvoorden HJ, et al. Effect of intravenous paracetamol on postoperative morphine requirements in neonates and infants undergoing major noncardiac surgery: a randomized controlled trial. JAMA 2013; 309: 149-54.

50. Sinatra RS, Jahr JS, Reynolds LW, Viscusi ER, Groudine SB, Payen-Champenois C. Efficacy and safety of single and repeated administration of 1 gram intravenous acetaminophen injection (paracetamol) for pain management after major orthopedic surgery. Anesthesiology 2005; 102: 822-31

51. Gregoire N, Hovsepian L, Gualano V, Evene E, Dufour G, Gendron A. Safety and pharmacokinetics of paracetamol following intravenous administration of $5 \mathrm{~g}$ during the first $24 \mathrm{~h}$ with a 2-g starting dose. Clin Pharmacol Ther 2007; 81: 401-5.

52. Oscier CD, Milner QJ. Peri-operative use of paracetamol. Anaesthesia 2009; 64: 65-72.

53. Wininger SJ, Miller H, Minkowitz HS, Royal MA, Ang RY, Breitmeyer JB, et al. A randomized, double-blind, placebo-controlled, multicenter, repeat-dose study of two intravenous acetaminophen dosing regimens for the treatment of pain after abdominal laparoscopic surgery. Clin Ther 2010; 32: 2348-69.

54. Candiotti KA, Bergese SD, Viscusi ER, Singla SK, Royal MA, Singla NK. Safety of multiple-dose intravenous acetaminophen in adult inpatients. Pain Med 2010; 11: 1841-8.

55. Graham GG, Scott KF, Day RO. Tolerability of paracetamol. Drug Saf 2005; 28: 227-40.

56. Benson GD, Koff RS, Tolman KG. The therapeutic use of acetaminophen in patients with liver disease. Am J Ther 2005; $12: 133-41$.

57. Adams SS. The propionic acids: a personal perspective. J Clin Pharmacol 1992; 32: 317-23.

58. Smith HS, Voss B. Pharmacokinetics of intravenous ibuprofen: implications of time of infusion in the treatment of pain and fever. Drugs 2012; 72: 327-37.

59. Scott LJ. Intravenous ibuprofen: in adults for pain and fever. Drugs 2012; 72: 1099-109.

60. Cashman JN. The mechanisms of action of NSAIDs in analgesia. Drugs 1996; 52 Suppl 5: 13-23.

61. Rao P, Knaus EE. Evolution of nonsteroidal anti-inflammatory drugs (NSAIDs): cyclooxygenase (COX) inhibition and beyond. J Pharm Pharm Sci 2008; 11: S81-110.

62. Vane JR, Botting RM. Mechanism of action of nonsteroidal anti-inflammatory drugs. Am J Med 1998; 104: S2-8.

63. Vane JR, Botting RM. Anti-inflammatory drugs and their mechanism of action. Inflamm Res 1998; 47 Suppl 2: S78-87.

64. Van Hecken A, Schwartz JI, Depre M, De Lepeleire I, Dallob A, Tanaka W, et al. Comparative inhibitory activity of rofecoxib, meloxicam, diclofenac, ibuprofen, and naproxen on COX-2 versus COX-1 in healthy volunteers. J Clin Pharmacol 2000; 40: 1109-20.

65. Warner TD, Giuliano F, Vojnovic I, Bukasa A, Mitchell JA, Vane JR. Nonsteroid drug selectivities for cyclo-oxygenase-1 rather than cyclooxygenase-2 are associated with human gastrointestinal toxicity: a full in vitro analysis. Proc Natl Acad Sci U S A 1999; 96: $7563-8$.

66. Morris PE, Promes JT, Guntupalli KK, Wright PE, Arons MM. A multi-center, randomized, double-blind, parallel, placebo-controlled trial 
to evaluate the efficacy, safety, and pharmacokinetics of intravenous ibuprofen for the treatment of fever in critically ill and non-critically ill adults. Crit Care 2010; 14: R125.

67. Pavliv L, Voss B, Rock A. Pharmacokinetics, safety, and tolerability of a rapid infusion of i.v. ibuprofen in healthy adults. Am J Health Syst Pharm 2011; 68: 47-51.

68. Southworth S, Peters J, Rock A, Pavliv L. A multicenter, randomized, double-blind, placebo-controlled trial of intravenous ibuprofen 400 and $800 \mathrm{mg}$ every 6 hours in the management of postoperative pain. Clin Ther 2009; 31: 1922-35.

69. Kroll PB, Meadows L, Rock A, Pavliv L. A multicenter, randomized, double-blind, placebo-controlled trial of intravenous ibuprofen (i.v.ibuprofen) in the management of postoperative pain following abdominal hysterectomy. Pain Pract 2011; 11: 23-32.

70. Singla N, Rock A, Pavliv L. A multi-center, randomized, double-blind placebo-controlled trial of intravenous-ibuprofen (IV-ibuprofen) for treatment of pain in post-operative orthopedic adult patients. Pain Med 2010; 11: 1284-93.

71. Promes JT, Safcsak K, Pavliv L, Voss B, Rock A. A prospective, multicenter, randomized, double-blind trial of IV ibuprofen for treatment of fever and pain in burn patients. J Burn Care Res 2011; 32: 79-90.

72. Krudsood S, Tangpukdee N, Wilairatana P, Pothipak N, Duangdee C, Warrell DA, et al. Intravenous ibuprofen (IV-ibuprofen) controls fever effectively in adults with acute uncomplicated Plasmodium falciparum malaria but prolongs parasitemia. Am J Trop Med Hyg 2010; 83: 515.

73. Bernard GR, Wheeler AP, Russell JA, Schein R, Summer WR, Steinberg KP, et al. The effects of ibuprofen on the physiology and survival of patients with sepsis. The Ibuprofen in Sepsis Study Group. N Engl J Med 1997; 336: 912-8.

74. Evans AM, Nation RL, Sansom LN, Bochner F, Somogyi AA. Effect of racemic ibuprofen dose on the magnitude and duration of platelet cyclo-oxygenase inhibition: relationship between inhibition of thromboxane production and the plasma unbound concentration of $\mathrm{S}(+)-$ ibuprofen. Br J Clin Pharmacol 1991; 31: 131-8. 